\title{
GROUND PENETRATING RADAR AS REMOTE SENSING TECHNIQUE TO INVESTIGATE THE ROOT SYSTEM ARCHITECTURE
}

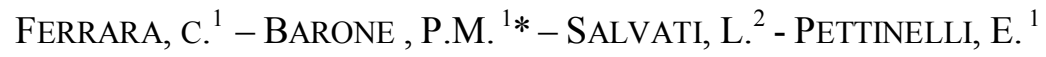 \\ ${ }^{1}$ Dept. Physics, University of ROMA TRE \\ Via della Vasca Navale, 8400146 Rome, Italy \\ (phone: +39-0657337021) \\ ${ }^{2}$ Agricultural Climatology and Meteorology Research Unit, Agricultural Research Council \\ Via del Caravita, 7/A 00186 Rome, Italy \\ (phone: +39-06695311) \\ *Corresponding author \\ e-mail: pmbarone@fis.uniroma3.it \\ (Received $18^{\text {th }}$ Apr 2012; accepted 22 ${ }^{\text {nd }}$ July 2014)
}

\begin{abstract}
Ground Penetrating Radar (GPR) is a remote-sensing technique widely applied in archaeology, engineering and environmental sciences. It is a non-invasive geophysical method which uses electromagnetic pulses to create an "image" of the shallow subsurface. In recent years, GPR gained popularity in forestry, thanks to its application in water content estimation, root stress evaluation, root biomass modelling, and roots location. In this paper we present the results of two radar surveys aimed at reconstructing the geometric features of root systems buried at shallow subsurface, thanks to a multiprofile data acquisition and to the use of a three-dimensional software package. Our results show the potentiality of this approach as a reconnaissance method before performing any destructive test.
\end{abstract}

Keywords: Remote Sensing, Ground Penetrating Radar, Root, Forestry

\section{Introduction}

Schowengerdt (2007) describes Remote Sensing as an attempt to measure something "at distance", i.e. without any "contact with the target", by means of some propagating signal. All geophysical methods can be considered, in general, Remote Sensing techniques, being able to remotely measure "the contrast" between the physical properties of the background and the target under investigation. Very few of those, however, are able to produce a full image of the subsurface, where the geometry and the position in space of the buried objects can be clearly determined. Ground Penetrating Radar (GPR) fulfils rather well these requirements, being capable to produce a detailed map of the subsurface using radio waves generated just above the ground surface (Jol, 2009; Daniels, 2004; Annan 2004). The interaction between the electromagnetic waves and the buried targets, produces an electromagnetic image similar to ultrasound images used in diagnostic medicine.

The main advantage of GPR is its capability to detect, in a non-destructive way, the vertical and horizontal dielectric anomalies associated with natural or manmade subsurface variability like: lithology, water content and bulk density changes, voids or buried objects, liquid or solid waste disposal, etc.

For this reason, GPR has been widely used in archaeology, engineering, hydrogeology, environmental sciences, and recently has also been applied in forestry, with different applications as root detection, root damages in urban context, root biomass evaluation, carbon allocation, water content variations, analyses on standing

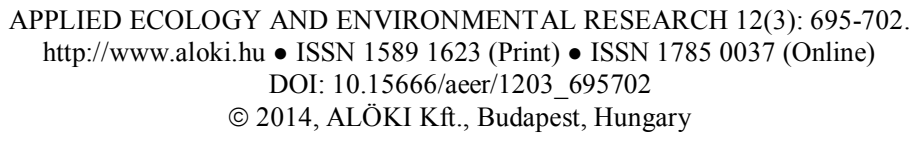


tree stems, control of the tree growth, as shown in Barton \& Montagu, 2004; Cermák et al. 2000 ; Cox et al.,2005; Cui et al., 2011; Dannoura et al.,2008 ; Hirano et al., 2009 ; Hruška et al., 1999 ;Leucci, 2010 ; Stokes et al.,2002 ; and Stover et al., 2007.

Furthermore, GPR has also been tested in combination with other geophysical techniques, e.g. Amato et al., 2008 ; Perez-Gracia et al. (2010), Rahjens et al. (2003), Rossi et al. (2011), Zanetti et al. (2011), and Zenone et al. (2008), showing the validity of such a multi-technique approach in developing different strategies to preserve tree roots and trees, as also described in Danjon \& Reubens (2008), and in Allred et al. (2011).

The potential use of GPR in forestry becomes even more evident if we take into account that to study the relationships between vegetation and the urban environments, or to estimate the biomass of tree roots, the traditional investigations are carried out in a very invasive way. In fact, soil and roots are usually sampled throughout cores, pits, or trenches, and the roots are collected, sieved, washed dried, and weighted, e.g. Butnor et al. 2001; Butnor et al. 2003. This method is destructive, labour-intensive, and not very useful to measure the lateral extent of a root system. Conversely, GPR is capable to map in a pseudo-3D fashion, with high vertical and horizontal resolution, the root system architecture, reducing the amount of root samples needed for quantitative analysis.

In this work, we show some examples of GPR surveys aimed at detecting and reconstructing the spatial distribution of the root system in different locations and soil conditions.

\section{The GPR technique}

GPR is a geophysical method which uses electromagnetic (em) waves, typically in the frequency range 10-3000 $\mathrm{MHz}$, to image structures and features buried in the ground. The physical principle of GPR detection, is based on the dielectric contrast between the buried target and the background material. Such a contrast can be produced in several ways: by spatial changes in the physical-chemical property of the sediments or the soil, changes in water content and bulk density of the material, or even by the presence of different objects in the subsoil like voids, rocks and boulders, wood, or manmade materials like metal and plastic targets. In general, if there is a detectable contrast between different subsurface objects, this can generate strong signal reflections which can be clearly identified on a GPR image (Annan, 2004; and Jol, 2009).

The equipment used in all GPR systems consists of four main elements: a transmitting unit; a receiving unit; a control unit; and a display unit. The transmitter produces a short duration, high voltage pulse. This pulse is applied to the transmitting antenna (Tx), which radiates it into the ground. The receiving antenna ( $\mathrm{Rx})$ collects the signals coming from the material under investigation, which are amplified and formatted for display, by the control unit, as depicted in Fig. 1.

The radar measures the signal amplitude vs. time (two-way travel time), for each position of the Tx-Rx on the ground. The data are collected moving the Tx-Rx system along a profile, so that a bi-dimensional radar cross-section having the two-way travel time on the $\mathrm{Y}$ axis and the antennas position on the $\mathrm{X}$ axis is obtained for each collected profile. To estimate the depth of the target (i.e. to convert time in depth) a simple calibration technique can be used, as illustrated in Annan, 2004, even though in complicated subsurface scenarios more refine algorithms should be applied, (Annan, 2004; and Jol, 2009). The velocity and the attenuation of the radar signals depend on the 
electromagnetic properties of the soil, which can be frequency-dependent quantities. In particular, in common geo-materials the maximum investigation depth decreases rapidly with increasing frequency due to the signal attenuation; this explain why almost all subsurface radar systems operate at frequencies lower than $3 \mathrm{GHz}$. The antenna frequency also affects the vertical and the horizontal resolution achievable in a GPR image. The shorter is the time pulse width (i.e. the higher is the antenna frequency), the higher is the resolution.

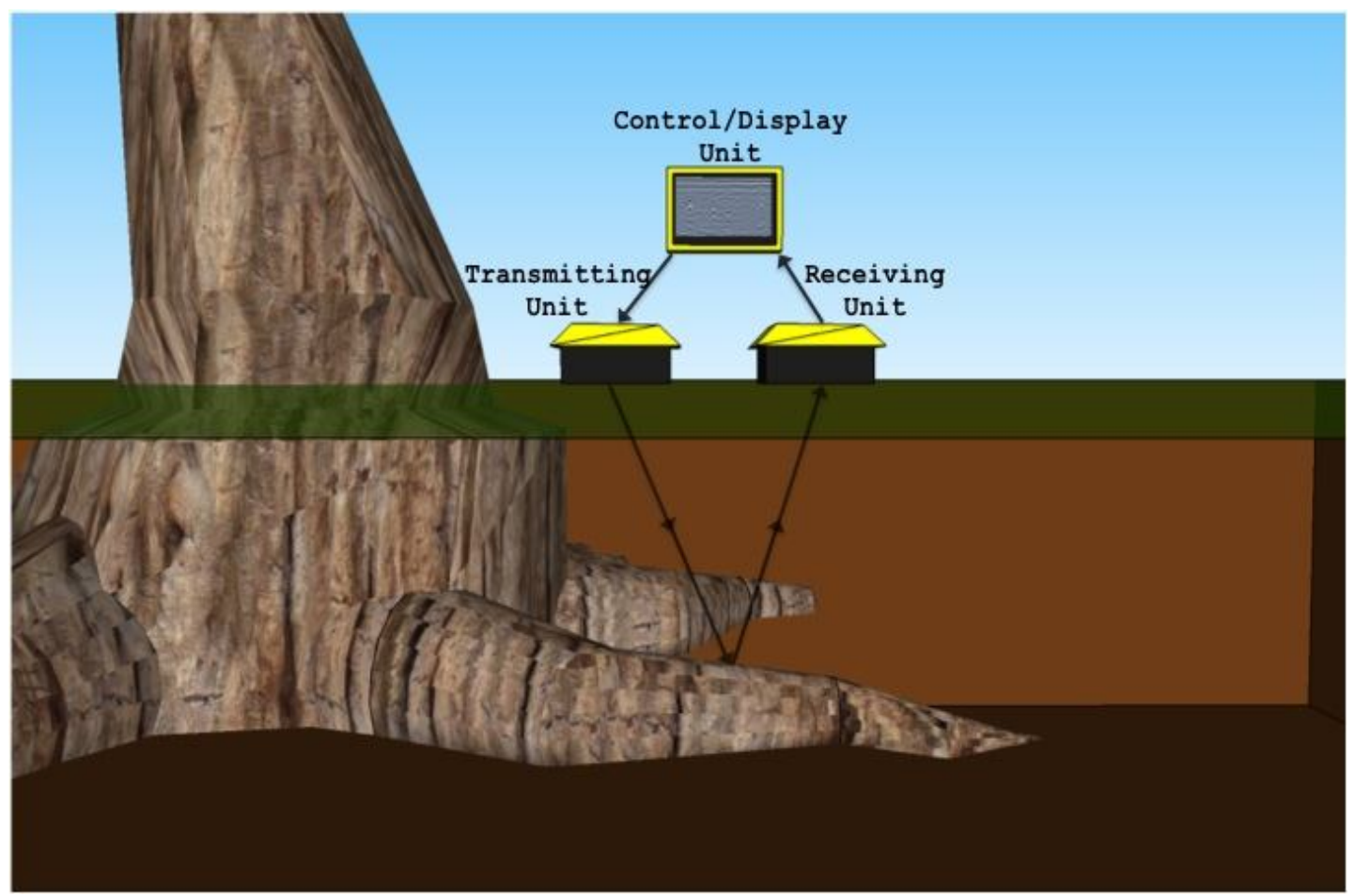

Figure 1. A schematic reconstruction of a GPR system for root investigations. The four main elements are the transmitting unit, the receiving unit, the control unit, and the display unit. A detectable contrast between different subsurface objects generates strong signal reflections which can be clearly identified on a GPR image.

In order to obtain a XY image of the subsurface, the radar data should be collected in multi-profile mode, where the profiles are acquired parallel to each other, at a fixed distance. This technique allows to create XY time (or depth) slices, in which the lateral geometry of the targets can be identified, i.e. Jol 2009. A further processing of the data collected on a XY grid, allows a pseudo-3D visualization of the subsurface, throughout the countering of the anomalies generated by the electromagnetic contrast between the target and the background material. The final results is a three-dimensional representation of the subsurface using the isosurfaces to display a surface of constant data value in three dimensions (Pettinelli et al., 2011).

\section{Case studies for subsurface roots detection}

In the following, we present two examples of radar investigations aimed at mapping the root system, performed in Rome (Italy) in different locations. 
The first case study reported here, is a GPR survey collected in the San Sebastiano Park (Rome, Italy) originally planned for archaeological purposes. Indeed, the correct detection of tree roots in archaeological areas is of paramount importance to distinguish between natural and manmade targets, and to define to what extent a root system has "invaded" the ruins present at shallow depth. The area $(40 \mathrm{x} 10 \mathrm{~m})$ was investigated using a bistatic GPR system (Fig.2A), equipped with $250 \mathrm{MHz}$ antennas (PulseEkko Pro by Sensors \& Software, Inc). The survey was performed acquiring a multi-profile $Y$ grid, (for a total of 20 parallel lines) with a line spacing of $0.50 \mathrm{~m}$ and a step-size of $0.05 \mathrm{~m}$. The second case illustrates the results of a GPR survey carried out inside the cloister of the Physics Department of the University of Roma Tre. The work was aimed at detecting the buried residual roots, still present in an area where a big tree was previously removed. Figure $3 \mathrm{~A}$ shows the bistatic $500 \mathrm{MHz}$ Noggin Plus GPR system (Sensors \& Software, Inc) used for the measurements. The area $(14 \times 12 \mathrm{~m})$ was investigated collecting a multi-profile $\mathrm{Y}$ grid (for a total of 26 parallel lines) with a line spacing of $0.50 \mathrm{~m}$ and a step-size of $0.02 \mathrm{~m}$.

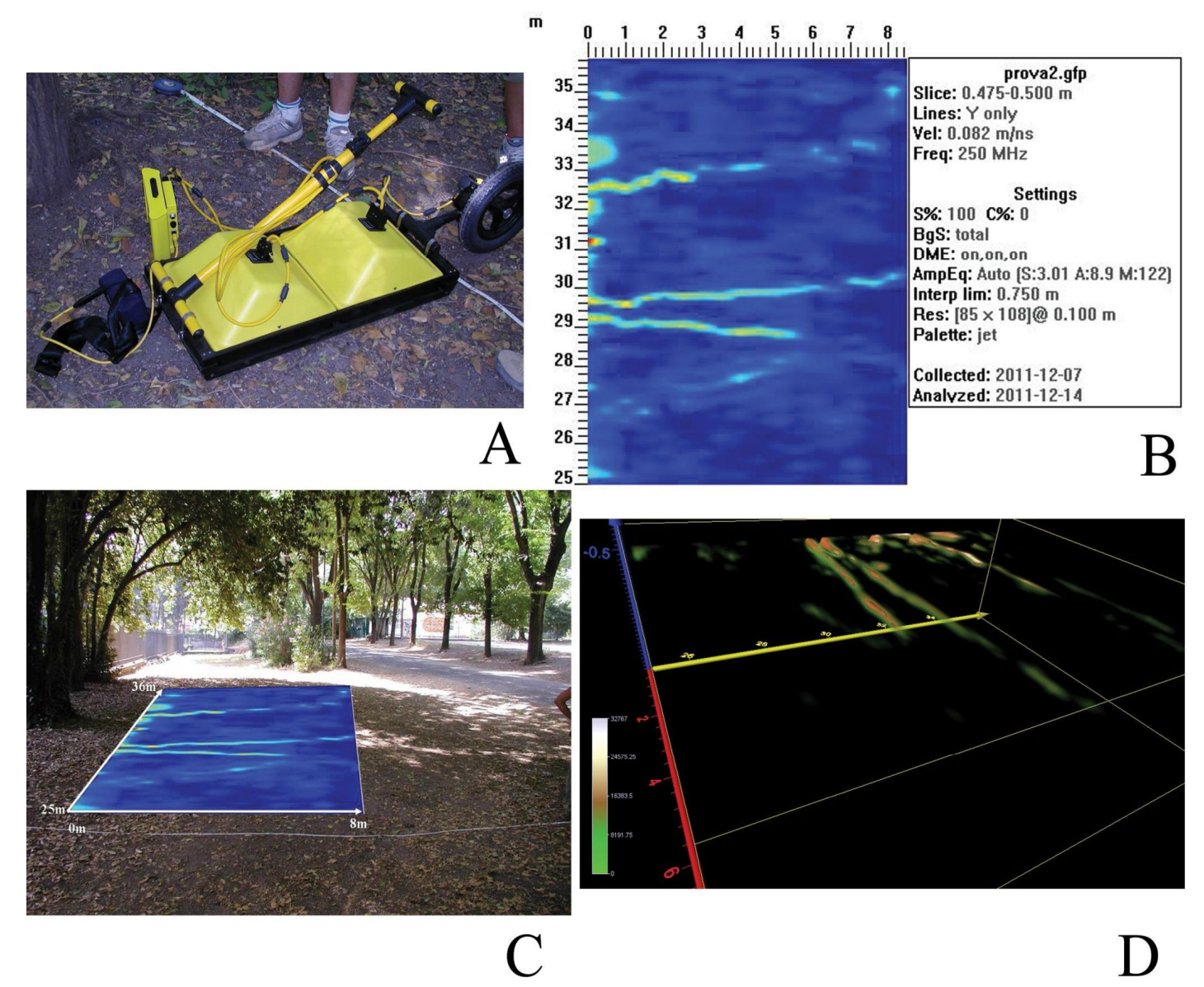

Figure 2. The GPR results acquired in San Sebastiano Park. Figure $2 \mathrm{~A}$ shows the $250 \mathrm{MHz}$ $G P R$ used during the investigation; Figure $2 B$ illustrates the $2 D$ penetration map (about $0.50 \mathrm{~m}$ depth) of the GPR anomalies; in Figure $2 C$ the overlap clarifies the correlation between the GPR anomalies and the roots beneath the soil; in Figure 2D there is the pseudo-3D reconstruction of the root system. 
Fig. $2 B$ depicts the radar map relevant to site 1, showing a $2 \mathrm{D}$ depth slice (at about $0.5 \mathrm{~m}$ ) obtained interpolating the radar data collected on the single lines, using a pulse velocity in the soil of $\mathrm{v}=0.082 \mathrm{~m} / \mathrm{ns}$ (estimated using the hyperbola calibration technique). The superposition of the radar map to the photo of the investigated area (Fig. 2C), allows to correctly locate the elongated anomalies detected by the radar, and to relate those with the tree root system architecture. The geometry of the roots is better visible if a pseudo-3D representation is used, as shown in Fig. 2D. In fact, if the data quality is high, and the radar anomalies are well visible also at depth (as in the case study presented here), the XYZ data volume reconstruction can be useful to better identify the target orientation, dimension and shape.

The second radar map (Fig.3B) depicts the results of the survey collected at Roma Tre University. The depth slice, superimposed to the photo of the investigated area (Fig. $3 C$ ), clearly shows various anomalies present in the subsoil due to pipes or other targets buried when the yard was built. In particular, Fig. $3 D$ shows the presence of an elongated anomaly, located near the position of the removed tree at a depth of about
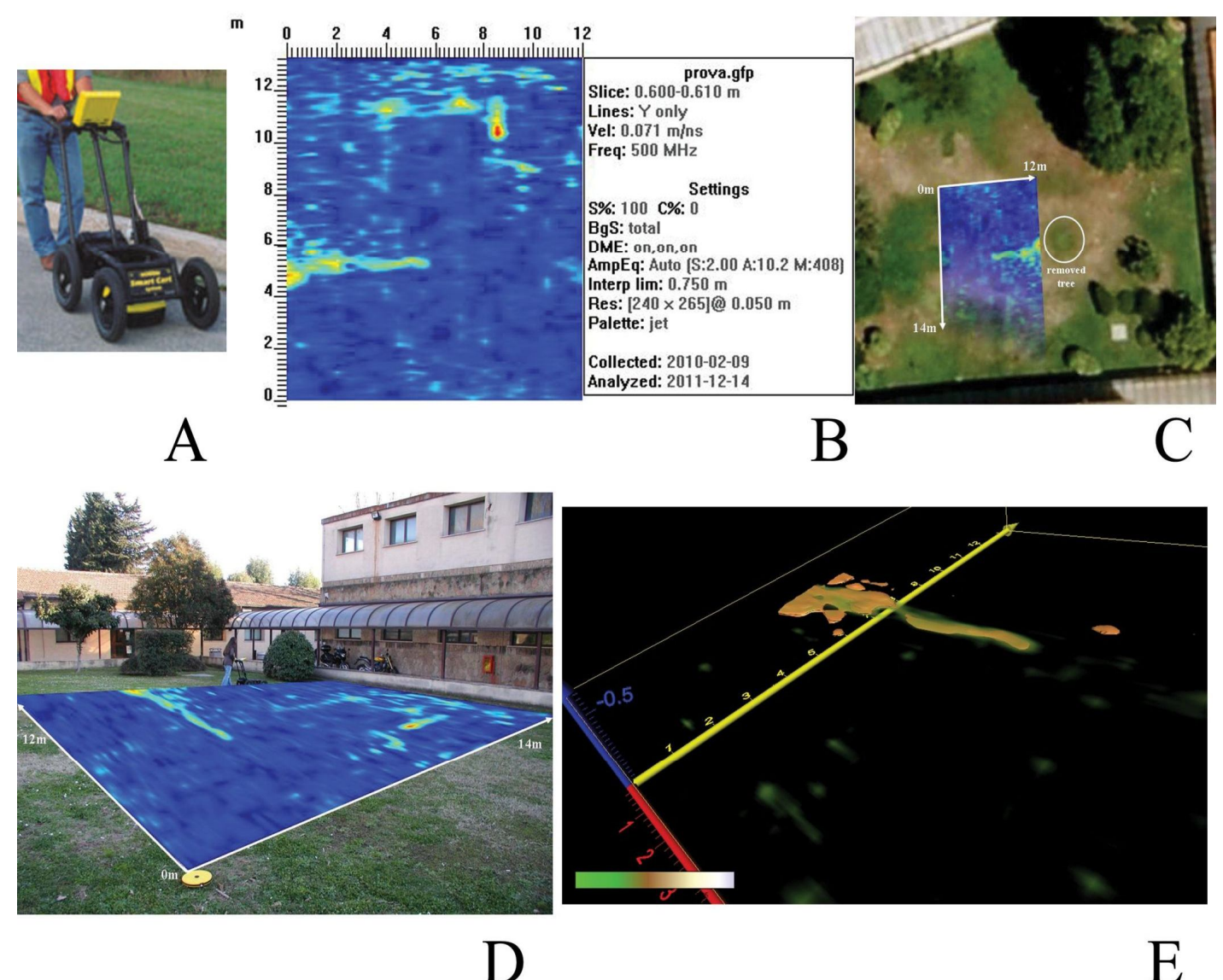

B
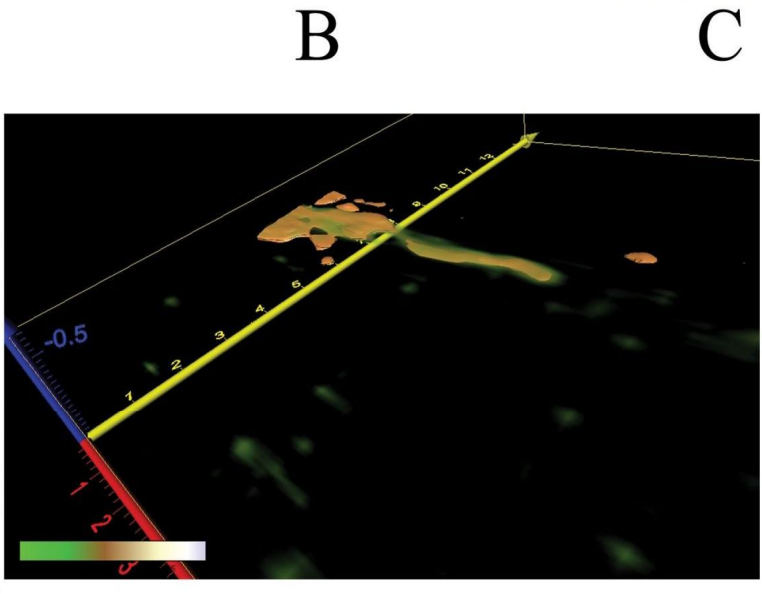

$\mathrm{D}$

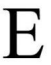

Figure 3. The GPR results acquired in the cloister of the Physics Department of the University of Roma Tre. Figure $3 A$ shows the $500 \mathrm{MHz}$ GPR used during the investigation; Figure $3 B$ illustrates the amplitude 2D map (about $0.60 \mathrm{~m}$ depth) of the GPR anomalies; in Figure $3 C$ it is evident the previous position of the removed tree and the GPR anomaly; in Figure $3 D$ the overlap clarifies the correlation between the GPR anomalies and the remain roots in the subsurface; in Figure $3 E$ there is the pseudo-3D reconstruction of the remain root. 
$0.60 \mathrm{~m}(\mathrm{v}=0.072 \mathrm{~m} / \mathrm{ns})$, which indicates the presence of some root relict. Again, if the data are represented in a XYZ space (Fig. $3 E$ ), the geometric features, i.e. orientation, shape and size, are much better defined, generating a more accurate reconstruction of the buried targets.

\section{Final considerations}

In this technical advance we have discussed the potentials of Ground Penetrating Radar as remote-sensing technique applied to forestry. The non-invasive nature of this geophysical method makes it appealing in all those applications where the common techniques used require the destruction of the samples. GPR is capable to create an electromagnetic image of the targets buried in the soil, allowing a detailed 3D reconstruction of their position and form. This is particularly important in roots system architecture study, where the alternative is the excavation or coring of the roots. Moreover, a part from very conductive soils, where the attenuation drastically reduces the maximum penetration depth of the radar pulses, this method can be successfully applied to every type of material from snow and ice to asphalt or dry sand. It is important to notice, however, that this technique is not able per se to define the nature of the object, e.g. metal, wood or rock, but can still be used as a reconnaissance method before performing any destructive test.

Another important advantage of this type of technique is its fast real-time acquisition, which allow to create a very large georeferenced (using a D-GPS) data volume. This aspect is particularly important for long term monitoring, where the evolution and development of the root system should be followed for months or years. Besides the capability to produce detailed maps of the subsurface, GPR can also be used to quantitatively estimate the water content in the soil or in the tree trunks, as well as to detect the presence of defects or voids in the wood. Moreover, the flexibility and reliability of the method permit a wide use in urban and rural environments, to address different problems like, tree protection during constructions, tree selection and landscape plan review, GIS compatible tree inventories, street tree management plans, plant health care planning and hazard evaluations.

Finally, some considerations should be made on the economic value of this type of technique: the moderate cost of the equipment with respect to those used to excavate or drill the soil, together with the fast acquisition time in large areas, make GPR quite competitive for forestry applications.

\section{REFERENCES}

[1] Allred B, Butnor J, Corwin DL, Eigenberg R, Farahani H, Johnsen KH, Lambot S, McInnis D, Pettinelli E, Samuelson L, Woodbury B (2011): Agricultural Geophysics. In: Subsurface Sensing (Turk AS, Hocaoglu AK, Vertiy AA eds). Wiley, Hoboken, NJ, USA, pp. 618-644.

[2] Amato M, Basso B, Celano G, Bitella G, Morelli G, Rossi R (2008): In situ detection of tree root distribution and biomass by multi-electrode resistivity imaging.- Tree Physiology 28: 1441-1448., ISSN: 0829-318X.

[3] Annan PA (2004): Ground penetrating radar: principles, procedures \& applications. Sensors \& Software Inc., Mississauga ON, Canada. 
[4] Barton CVM, Montagu K.D. (2004): Detection of tree roots and determination of root diameters by ground penetrating radar under optimal conditions. - Tree Physiology 24: 1323-1331., ISSN: 0829-318X.

[5] Butnor JR, Doolittle JA, Johnsen KH, Samuelson L, Stokes T, Kress L (2003): Utility of GPR as a root biomass survey tool in forest systems. - Soil Science Society of America Journal 67: 1607-1615.

[6] Butnor JR, Doolittle JA, Kress L, Cohen S, Johnsen KH (2001): Use of groundpenetrating radar to study tree roots in the southeastern United States. -Tree Physiology 21: 1269-1278., ISSN: 0829-318X.

[7] Cermák J, Hruška J, Martinková M, Prax A (2000): Urban tree root systems and their survival near houses analyzed using ground penetrating radar and sap flow techniques. Plant and Soil 219: 103-116., ISSN: 0032-079X.

[8] Cox KD, Scherm H, Serman N (2005): GPR to detect and quantify residual root fragments following peach orchard clearing. - Hort Technology 15: 600-607.

[9] Cui XH, Chen J, Shen JS, Cao X, Chen XH, Zhu XL (2011): Modelling tree root diameter and biomass by ground-penetrating radar. - Science China Earth Science 54: 711-719., doi: 10.1007/s11430-010-4103-z.

[10] Daniels DJ (2004): Ground Penetrating Radar. 2nd Edition. The Institution of Engineering and Technology, London UK., ISBN: 0863413609.

[11] Danjon F, Reubens B (2008): Assessing and analyzing 3D architecture of woody root systems, a review of methods and applications in tree and soil stability, resource acquisition and allocation. - Plant Soil 303: 1-34., doi: 10.1007/s11104-007-9470-7.

[12] Dannoura M, Hirano Y, Igarashi T, Ishii M, Aono K, Yamase K, Kanazawa Y (2008): Detection of Cryptomeria japonica roots with ground penetrating radar. - Plant Biosystems 142: 375-380., doi: 10.1080/11263500802150951.

[13] Hirano Y, Dannoura M, Aono K, Igarashi T, Ishii M, Yamase K, Makita N, Kanazawa Y (2009): Limiting factors in the detection of tree roots using ground-penetrating radar. Plant Soil 319: 15-24., doi: 10.1007/s11104-008-9845-4.

[14] Hruška J, Cermák J, Sustek S (1999): Mapping tree root system with ground-penetrating radar. - Tree Physiology 19: 125-130., ISSN: 0829-318X.

[15] Jol HM (2009): Ground penetrating radar: theory and applications. - Elsevier, Oxford UK., ISBN: 0444533486.

[16] Leucci G (2010): The use of three geophysical methods for 3D images of total root volume of soil in urban environments. - Exploration Geophysics 41: 268-278., doi: 10.1071/EG09034.

[17] Perez-Gracia V, Lorenzo H, Diaz-Peñalver N (2010): Forestry applications of groundpenetrating radar. - Forest System 19: 5-17., ISSN: 2171-5068.

[18] Pettinelli E, Barone PM, Di Matteo A, Mattei E, Lauro SE (2011): Radio waves technique for non-destructive archaeological investigations. - Contemporary Physics 52:121-130., doi: 10.1080/00107514.2010.545208.

[19] Rahjens RG, Doolittle JA, Mazur G, Siewert AR (2003): GPR as a tool for diagnosing shade tree soil problems. - Tree Care Industry Magazine NOVEMBER: 60-62.

[20] Rossi R, Amato M, Bitella G, Bochiccio R, Ferreira Gomes JJ, Lovelli S, Martorella E, Favale P (2011): Electrical resistivity tomography as a non-destructive method for mapping root biomass in an orchard. - European Journal of Soil Science 62: 206-215., doi: 10.1111/j.1365-2389.2010.01329.x.

[21] Schowengerdt RA (2007): Remote sensing: models and methods for image processing. 3rd Edition. - Academic Press, Elsevier, Burlington MA, USA., ISBN: 9780123694072.

[22] Stokes A, Fourcaud T, Hruška J, Cermák J, Nadyezhdin N, Praus L (2002): An evaluation of different methods to investigate root system architecture of urban trees in situ: I. Ground penetrating radar. - Journal of Arboriculture 28: 1-9. 
[23] Stover DB, Day FP, Butnor JR, Drake BG (2007): Effect of elevated CO2 on coarse -root biomass in Florida scrub detected by ground-penetrating radar. - Ecology 88: 13281334., doi: 10.1890/06-0989.

[24] Zanetti C, Weller A, Vennetier M, Mériaux P (2011): Detection of buried tree root samples by using geoelectrical measurements: a laboratory experiment. - Plant Soil 339: 273-283.

[25] Zenone T, Morelli G, Teobaldelli M, Fischanger F, Matteucci M, Sordini M, Armani A, Ferré C, Chiti T, Seufert G (2008): Preliminary use of ground-penetrating radar and electrical resistivity tomography to study tree roots in pine forest and popular plantations. - Functional Plant Biology 35: 1047-1058., doi:10.1071/FP08062. 